Review Article

\title{
Review on the English Version of Hanvueng, A Baeu Rodo Scripture
}

\section{Lu Lianzhi}

School of Foreign Languages, Baise University, Baise, China

Email address:

To cite this article:

Lu Lianzhi. Review on the English Version of Hanvueng, A Baeu Rodo Scripture. International Journal of Language and Linguistics. Vol. 8, No. 2, 2020, pp. 82-87. doi: 10.11648/j.ij11.20200802.14

Received: March 18, 2020; Accepted: April 7, 2020; Published: April 23, 2020

\begin{abstract}
David Holm is an English native speaker of high proficiency in Zhuang language and Meng Yuanyao is a Zhuang native speaker of great familiarity with English. They worked together to produce an English version Hanvueng: The Goose King and the Ancestral King: an Epic from Guangxi in Southern China. This book is translated from the vernacular scriptures of the Zhuang Ethnic Group, one of the Chinese minorities. It was published in 2015. Based on a careful reading of this book, the author of this article argues: firstly, this book is of ethnographic Zhuang-English translation because it was translated directly from Zhuang language to English language by adopting ethnography methods of fieldwork and it provides numerous cultural and linguistic notes for those items that may be difficult for readers to understand; secondly, it characterizes the joint efforts of in-and-out governmental organizations, including various organizations, work units, and research projects, and the collaborative work of Zhuang and English giants, authority figures, involving officials, scholars, and common people; thirdly, it is no doubt a good example of ethnographic thick-translation version in translating Zhuang classics into English. This book provides a new approach to translating and introducing minority ancients works to the outside world to promote international communication and it is of great referential significance for "going global" strategy of Chinese minority classics.
\end{abstract}

Keywords: Hanvueng, Baeu Rodo Scripture, Ethnography, David Holm

\section{Introduction}

After the publication of his two books Recalling Lost Souls: The Baeu Rodo Scriptures, Tai Cosmogonic Texts from Guangxi in Southern China (2003) and Killing a Buffalo for the Ancestors: a Zhuang Cosmological Text from Southwest China (2004), David Holm, together with his co-author Meng Yuanyao, produced another book Hanvueng: The Goose King and the Ancestral King: an Epic from Guangxi in Southern China (shortened as Hanvueng afterwards in this article). It is an English version with the Hanvueng scripture, one of the the vernacular scriptures of the Zhuang Ethnic Group called Baeu Rodo scriptures, as its source text. They had it published as a book in 2015. The three above-mentioned English versions are translated on the basis of the book of The Baeu Rodo Scriptures: An annotated Translation (1991). They are closely related to each other and make a series of the translation volumes of the Baeu Rodo Scriptures. Baeu Rodo was an apical ancestor of the Zhuang who have a population of about 17 million and ranks as the largest minority in China. The Baeu Rodo Scriptures are ritual manuscripts written in Zhuang character script and dedicated to the worship of Baeu Rodo. They are also called "ancient songs", that is to say, folktales about the exploits and inventions of Baeu Rodo. Based on selections from nine different manuscripts, some of which were centuries old and whose texts were written in predominantly five-syllable verse, the Chinse edition of The Baeu Rodo Scriptures: An annotated Translation was a collection of scriptures totaled over 1230 pages and presented 27 texts. It was published in Nanning, the provincial capital of Guangxi in China by Guangxi People's Publishing House in 1991. Its texts were arranged according to mythic themes, beginning with the creation of heaven and earth and proceeding in mytho-chronological order through the creation of humankind, the creation water, of fire, of buffaloes, oxen, pigs, hens and ducks, down to the invention of writing and the calendar, and the creation of emperors and local chieftains. 
Then the work comprised the texts whose main purpose was the regulation of interpersonal relationships between stepbrothers, father and son, mother and daughter, mother-in-law and daughter-in-law, and so on, along with texts related to life-cycle rituals. David Holm pointed out that "the original collection of materials proved too extensive to be published within the confines of a single volume, and I have accordingly decided to present the cosmogonic texts first, leaving the more disparate texts of the second half of the original collection for publication elsewhere [1]." This is how the English version of Hanvueng was produced as a separate volume.

Hanvueng was published by Koninklijke Brill, NV, Leiden, The Netherlands. It presents an annotated edition of a traditional Zhuang text, which is a long narrative song that is current in the western part of Guangxi Zhuang Autonomous Region (GZAR) and contiguous parts in Guizhou and Yunnan provinces. The text itself is in the traditional Zhuang character script, an instance of a Sinoxenic script in which the Chinese character script has been borrowed and modified to write a different language known as Zhuang, a vernacular script rather than a standardized script used at court. In The Baeu Rodo Scriptures: An annotated Translation, the text under discussion here is complete with interlinear glosses and transcriptions, textual and ethnographic notes, and photographs of the original manuscript pages. The English version of Hanvueng consists of the following parts: list of illustrations, preface, list of abbreviations, conventions, introduction, English translation, interlinear transcription, textual and ethnographic notes, glossary and concordance, Chinese character index, index of vernacular characters and allographs, Zhuang characters and allographs, Zhuang character index, English-Zhuang index, subject index, bibliography, and photo-reproduction of manuscript pages. Based on detailed reading and close examination of the translation work, the author of this article argues that the English version of Hanvueng is an ethnographic Zhuang-English translation, an effective cooperation between Zhuang and English native speakers, and a typical example of thick translation.

\section{An Ethnographic Zhuang-English Translation}

Unlike many other translations of minority works in China which went through the process of "minority language Chinese - foreign language", Hanvueng is translated directly from Zhuang language to English language by adopting ethnography methods of fieldwork. The English translation text is put in a network of cultural and linguistic notes of the Zhuang, which makes this work an ethnographic study version.

\subsection{An Introduction to Hanvueng}

Hanvueng presents an annotated translation of a Zhuang ritual manuscript written in the traditional Zhuang character script (also called the "old Zhuang script"). It is a narrative of rivalry and murderous enmity between two royal stepbrothers recited by "boumo" (an indigenous ritual specialist) to regulate the interpersonal relationship between brothers. In Zhuang, "mo" means "to recite (in a low voice), and hence "to mutter" or "mumble" $[2,3]$. Of course, the boumo are heirs to a quite ancient tradition and recitation of texts is a salient feature of the rituals performed by boumo. In Zhuang villages, boumo are able to perform a wide range of rituals on behalf of the living, such as exorcisms, sacrifices and healing rituals for people, domestic animals, and crops. They are called upon for miscellaneous tasks including calling lost souls, selecting auspicious days for wedding, funerals, and house-building, conducting divination by means of eggs, chicken thigh-bones, and some others. In the case of Hanvueng, it is of oral composition and unstandardized and varies from place to place. The name Hanquengz is written in various ways in Zhuang texts and there is no generally accepted explanation for such variants. The author argues that such variants may result from poor communication between boumo who were highly literate and wrote down the oral texts into Old Zhuang scripts. At that time, there were no planes, no trains, no buses, and no boats, people had to walk to visit friends and relatives. The fact that Zhuang people then lived in mountainous areas made it more difficult for people to travel to visit each other. In such circumstances, it was no wonder that boumo borrowed different Chinese characters to represent a Zhuang sound in various localities of Zhuang dwellers just because different Chinese characters may sound the same. The variants of the title Hanvueng is exactly an illustration. However, though different in details, the gist of the narrative is more or less the same.

The narrative mainly involves events of remarriage of the king, feuding between stepbrothers, death by violence, outbreaks of smallpox, and a range of other cases. It goes that a king in ancient times lost his wife and lived alone with his son. In the six years of his widowerhood, he had to patch his own clothes, carry his won firewood, fetch his own water, and do his own cooking. His kingdom fell into disorder and he was thinking of abandoning his kingship. The elders in the kingdom came together to consult, and then they proposed that the king should take a second wife. He agreed and sent for matchmakers. After repeated hard work of his matchmakers, he married a widow woman who brought her own son with her. After his remarriage, the second wife played upon him until he favored the son that she brought with her than his son by his first wife. The wife and her son plotted to kill the son by the first wife and made the younger stepson the designated heir (titled as the "ancestral king", "covueng" in Zhuang language). They bestowed the title of "goose king" ("hanvueng" in Zhuang) on the son by the first wife who had originally been designated heir.

As a good-hearted boy, Hanvueng bore all the unfair things without complaints. Covueng enjoyed the special rights of the royal heir, eating rice and fish for his breakfast and riding a horse around the kingdom. To the contrary, Hanvueng was living a tragic life, eating millet and grass stems and working 
as Covueng's slave being cursed and abused. They became enemies and started fighting. The property was divided, and the paddy-fields, young serfs, pretty maids, and the gold and silver all went to Covueng. In despair, Hanvueng fled to Wudang Mount and then to Vitnam (Jiaozhi at that time). The conflicts between the stepbrothers continued. They argued and fought. Their conflicts gave rise to wars. The younger brother was not strong enough to fight his elder brother and he asked his brother to come back but the latter refused. Hanvueng did not come back until his father was serious ill and near death. To please their bedridden father, the two brothers went hunting for the requested muntjac meat. During hunting, Covueng tried to kill Hanvueng several times. Then the father requested to have water from a deep spring. As Hanvueng descended into the deep spring, Covueng took the chance and tried to kill his elder brother by dropping earth, stones and sabres. Fortunately, Hanvueng called on the water god and the thunder god to save him and he was rescued, flew up to the sky, and became a ruler in the heaven. As punishment, Hanvueng sent down drought, plagues and floods on the murder Covueng. The earth was in chaos, full of disasters and deaths. At his wits' end, Covueng repented and offered restitution to Hanvueng. However, Hanvueng turned down his younger brother's offer. As a result, the two brothers made it an agreement that Hanvueng ruled the sky while Covueng governed his kingdom on the earth on the condition that Covueng was required to pay offerings of fruit, wine, tea, fish and buffalo. In this way, the two brothers enjoyed peace ever since [4].

\subsection{Ethnographic Features of Hanvueng}

According to Chris Baker, "Ethnography is an empirical and theorical approach inherited from anthropology whose central purpose is to generate details of holistic description and analysis of cultures based on intensive fieldwork [5]." Ethnography is the core concept of anthropology and has become a code word for a range of qualitative methods. Its research objects are others and the commonly-used methods are participant observation and in-depth interviews. "In seeking to present the meanings, feelings and cultures of others, ethnography has tended to rely on a realistic epistemology and has opened itself up to considerable critique [5]." Similarly, translation can be done by rendering words and expressions or concepts of the source culture by the closest equivalent words, expressions, or concepts in the target language. Both ethnography and translation deal with the interpretation of others' culture, so it is natural that the theory and methods of ethnography can be applied to translation studies. Such studies have been well done as in Christian J. Churchill's article Translation and Ethnography: The Anthropology Challenge of Intercultural Understanding (2005) and Kate Sturge's book Representing Others: Translation, Ethnography and the Museum (2007). Hanvueng, an English version of the Hanvueng scripture, demonstrates some ethnographic features of translation.

The English version Hanvueng is produced by means of intensive fieldwork with methods of participant observation and in-depth interviews. In the early 1990s, David Holm began a long-term collaboration with the Ancient Manuscripts Editing Office in Nanning, Guangxi. With the help of this office, David Holm had access to all the traditional manuscripts in the office's archives. In addition, he was arranged for travel and interviews with participants in the earlier national project to document the written traditions of China's national minorities. He visited villages from which the manuscripts were collected and had extended discussions with many scholars and quite a few boumo. While visiting Huang Ziyi, a native of the area from which the manuscript of Hanvueng came, he was able to obtain a recording of the entire text which was provided in CD format. David Holm said he "owe [s] a special debt to Mr. Huang, and also to Mr. Zhang Shenzhen and Mr. Luo Bin [6]." His fieldwork visits and interviews guaranteed that he might have fewer difficulties in his later work on his translation.

In Philippe Cardinal's view, "ethnography translation ought to make a reader (and what he or she takes for granted) stranger than others, or to use Venuti's words, 'to send the reader abroad' [7]." There is no doubt that the English version of Hanvueng is a signal contribution to the intercultural communication between the Zhuang and English peoples. The Hanvueng ritual text is of considerable importance for the study of Zhuang mythology and ritual. By translating the Hanvueng scripture into English, the translators encounter English readers with Zhuang culture which was unfamiliar to them. From Hanvueng, the reader will get to know that, in addition to the translation text itself, the Hanvueng scripture is recited by boumo mainly in situations where younger and elder brothers have quarreled and when their quarrels have led to lasting hatred, enmity and violence by referring to textual and ethnographic notes and others. The boumo use a modified form of the Chinese script to write the Hanvueng religious text in the Zhuang language, which is called the "Old Zhuang". It is a fact that the Zhuang script has never been standardized and varies from locality to locality. The same Zhuang word is frequently written in two or more different ways. The title "Hanvueng" is the exact case. It is written variously in Chinese characters of relatively close homophones when read in Zhuang. To produce his translated text, David Holm "review [s] various versions of the Hanvueng epic, discuss [es] the ritual context of recitation, and touch [es] briefly on some of the ways in which the text reflects themes of central importance to Tai-style chieftaincy [8]." Furthermore, David Holm provides information about poetic structure, language, and script. Such efforts help him to produce a typical translated text of an ethnographic study version.

\section{A Collaborative Effort}

The English version of Hanvueng is not produced in a single day. Its publication came after a long time of preparations and the collaborative efforts of many people from different levels, working as a success and providing a new approach to translating ancient documents of minority people into English. It represents a new trend in the practice of translating minority classics in the context of intercultural 
communication.

\subsection{Joint Effort of Parties}

Hanvueng is a collaborative work of authority figures and common people and is supported by various organizations and work units. Being one of the Baeu Rodo scriptures, Hanvueng is of great significance in the aspects of literature, culture, religion, history and scholarship with its theme reflecting the desire of peaceful co-existence and harmonious development of mankind and is collected by numerous scholars from the academic circle and the literary world led by the Guangxi Office for Ancient Manuscripts. After decades of hard work, including fieldwork visiting, manuscript collecting, selecting, recording, translating (because all materials are of Zhuang oral composition), annotating, editing, and proofreading, the Chinese edition of The Baeu Rodo Scriptures: An annotated Translation was published, a part of which is the Chinese text of Hanvueng, the source text for David Holm to translate. In translating this text, David Holm got much help from different levels of authorities, such as Mr. Zhang Shengzhen, a high-level provincial official who had devoted himself in retirement to promoting scholarship on the Zhuang, and Mr. Luo Bin, a deputy director of the Guangxi Office for Ancient Manuscripts. During his fieldwork visits, he enjoyed the hospitality of Zhuang folks, seeing boumo, observing rituals, photocopying scripts, and visiting scholars. Based on his field work, he fulfilled his tasks of transcribing Huang Ziyi's recitation of the text into International Phonetic Alphabet, confirming the pronunciation and meaning of each morpheme in the text, providing textual notes explaining doubtful readings, obscure words, and other such matters, consulting with Zhuang scholars about the cultural background of each line beyond the lexical level, and investigating the use of the text in ritual performance.

The publication of Hanvueng is co-produced by several research projects. David Holm's research was funded by the Australian Research Council through a Discovery Grant ('The Old Zhuang Script'), by the Chinang Ching-kuo Foundation for International Scholarly Understanding through a research grant ('Spirit Mediumship and Taoism in South China'), by the National Science Council in Taiwan for a project entitled 'Writing Systems, Literary and Orality in Southwest China, and by a further grant from the National Science Council in 2010-2011 enabled a follow-up visit to Guangxi and additional fieldwork [9].

\subsection{Strong Partnership of Giants}

Hanvueng is a strict Zhuang-English translation translated and annotated by two giants, David Holm and Meng Yuanyao. The former Dr. Holm is an English native speaker with high proficiency in Zhuang language. He was born in the United States and completed his doctoral thesis at Oxford University. His research interest covers Zhuang and Bouyei language and literature, Ethnography of the Tai-speaking peoples of Southwest China, Ritual and performance culture in Shaanxi province Taoism and spirit mediumship, and Decipherment of the Old Zhuang Script In the 1990s, he began work on the textual traditions and performance culture of the Zhuang, a Tai-speaking people and China's largest minority group. His work led to the publication of the three books about the Baeu Rodo scriptures. The latter Dr. Meng is a Zhuang native speaker with high proficiency in English. While working on this work, Mr. Meng was a professor of the Department of Minority Languages at the Guangxi University for Nationalities in Nanning. After completing his $\mathrm{PhD}$ thesis at the University of Melbourne, he spent two years on this project as a post-doctoral researcher. Before going to Melbourne, Mr. Meng was Deputy Director in the Research Office of the Guangxi Minority Languages Commission in Nanning for many years and was greatly familiar with a wide range of Zhuang dialects and other linguistic and cultural environments.

In translating Hanvueng, David Holm and Meng Yuanyao worked as partners. The division of labor for the translation book was given in the preface part by David Holm: "Meng Yuanyao undertook the transcription of Huang Ziyi's recitation and produced preliminary word glosses for all words in the text, and drafted a set of preliminary textual and thnographic notes in Chinese. The notes became the basis for a prolonged dialogue and follow-up investigations; the end result is a much-expanded set of notes in English. The notes contain background information on word usage, grammar, and pragmatics, as well as cultural and historical information. I was responsible for the grammatological and historical linguistic sections of the notes, for the three indices which accompany the text, and for drafting the final version [10]." The strong partnership of such two giants produced an ethnographic study version which is a milestone in Zhuang studies. Thanks to their hard work, their rigorous scholarship, and down-to-earth attitude, Hanvueng has a wide potential readership and it will make an impact across the fields of linguistics, history, anthropology, religious studies, and comparative literature.

\section{A Thick-translation Version}

David Holm is an ethnographic researcher-translator. He has long committed to the characteristic ethnographic research and English translation of the Zhuang language and culture, which is quite unique, pioneering and fruitful [11]. Abundant thick translation was applied to the work of Hanvueng. The notion of thick translation was first put forward by Kwame Anthony Appiah in 1993. He argued in his essay that "translation that seeks with annotations and its accompanying glosses to locate the text in rich cultural and linguistic context, is eminently worth doing [12]." The English version of Hanvueng is no doubt a good example of thick-translation work. The whole book of Hanvueng covers 641 pages in total. However, the translation text of the Hanvueng scripture itself is not very long. It is 1536 lines, taking only 38 pages from page 51 to page 89 . In addition, following the English translation of the text, the translators provide the Interlinear Transcription part, in which the five-character verse goes as 
follows: the first line is the old Zhuang Script, the second line is the international phonetic alphabet, the third line is the modern Zhuang spelling, and the fourth line is the word-for-word English translation, which runs from page 90 to page 282, taking 192 pages altogether. Such a layout of interlinear writing and follow-up notes aims at the English narration for English readers and creates the intercultural dialogue and ethnography of ethnic cultures, just as what is argued by Wang Zhiguo that interlinear writing was of great referential significance for "going global" strategy of Chinese minority literature [13]. In sum, the coverage of the two parts of the English translation and the Interlinear Transcription accounts for only $36 \%$. In other words, apart from the strict translation texts, the rest, $64 \%$ of the whole book, gives space to voluminous background for the source culture and the way that Zhuang people have thought and expressed themselves.

"Textual and Ethnographic Notes", which covers the pages from 183 to 469, is an expression of thick translation. The text itself has 1536 lines in total. Each line is annotated. There are 639 notes in all, involving each character which maybe difficult for readers to understand. The relevant information of an annotated term was provided in pronunciation, origin, variation, relation to Chinese character, historical and cultural connotation and so on. The translators succeed in putting the translated text in a network of rich linguistic and cultural context, helping readers to have a better appreciation of Zhuang culture. One of the annotations is given here for illustration, which the author will quote in part:

The last two characters in the line are 郎漢, which B (589:2) reads as Langhanq and translates as 郎汉 Langhan without further comment. However, this name appears again in the following line (16) and again in lines 18 and 25, and it is clear from the context that the personage otherwise known as Hanvueng is meant. Langz is a common rendering in Zhuang of Han loan-word 郎, MSC láng 'young gentleman', meaning a young man of noble parentage. Since Hanvueng was the son of a chieftain, this would be an appropriate designation. However, another possibility is that Langzhanq is a place-name... [14].

This is an annotation for "langzhanq", a proper noun translated as "Langhan" in line 15 in the text. The translators provide a lengthy annotation of 31 lines in one of its follow-up notes, aiming at conveying the message of "Langhan" with a wide cultural environment of cultural context, history and others. What was cited above shows the great serious and scientific attitude of the translators. In Hanvueng, numerous annotations are employed. The definition of annotation is that "translators add to translated texts in order to provide information they consider to be useful [15]." Also, an annotation is a note, comment, or concise statement of the key ideas in a text or a portion of a text and is commonly used in reading instruction and in research [16]. For some special terms such as some abbreviations, they gave full explanation in some other parts. In the above annotation, MSC stands for Modern Standard Chinese, B for the Chinse edition of The Baeu Rodo Scriptures: An annotated Translation (1991), and ZHCH for Zhuang-Han Dictionary. There are more than 600 such annotations in Hanvueng. They will redress the near total lack of Western-language sources dealing with the Zhuang people. The translators have done a splendid job of making an important cultural artefact of language and culture of the Zhuang accessible. The research methods brought to such a work are a model for later translators who are interested in translating the ancient works of minority groups in China into English or even other foreign languages.

\section{Conclusion}

World peace in the future depends on intercultural understanding. Different cultures are not simply groups of people who label the world differently; languages give us the means to shape our views of the world and languages are different from one another. The Hanvueng Scripture is one of the "living fossils" of Zhuang minority group in the south of China. The English version of Hanvueng is an access to the culture of the Zhuang people with its translation of ethnographic features and the application of thick translation. It is produced mainly by David Holm who had conducted plenty of fieldwork involving participant observation, in-depth interviews, and visits of numerous officials and scholars. It is a translation of strong partnership of two veterans, a native English professor and a native Zhuang learned scholar. Their efforts led to a strict Zhuang-English translation. There is no doubt that translation is a means to bridge cultures and the English version of Hanvueng is of wide potential readership and a model for translators of classic works to learn from. It is a new approach to translating and introducing minority ancients works to the outside world to promote international communication.

\section{Acknowledgements}

This article is part of the research findings supported by the National Social Science Fund of China through a research grant "On the English Translations of the Epic of Zhuang Baeu Rodo from the Perspective of Ethnographic Translation" (16BYY036). I am grateful for intellectual input from Huang Zhongxi, the director of the above-mentioned research project of national level, a professor of English, and a Zhuang native speaker whose research interest focuses on the translation of minority classics, and Han Jiaquan, a professor of English and a veteran in the circle of translation who has produced quite a few books on the studies of Chinese-English translation. Special thanks are due to David Holm and Meng Yuanyao, the translators of Hanvueng.

\section{References}

[1] David Holm, Recalling Lost Souls: The Baeu Rodo Scriptures, Tai Cosmogonic Texts from Guangxi in Southern China. Bangkok: White Lotus Co., 2004, p. xi.

[2] Zhang Shengzhen, Annotated Facsimile Edition of the Baeu Rodo Zhuang Mo Scriptures. Nanning: Guangxi People's Publishing House, 2004, p. 2941. 
[3] Huang Mingbiao, A New Version of Annotated Facsimile Edition of the Baeu Rodo Zhuang Mo Scriptures. Nanning: Guangxi People's Publishing House, 2016, vol. 3, p. 151.

[4] Zhang Shengzhen, The Baeu Rodo Scriptures: An annotated Translation. Nanning: Guangxi People's Publishing House, 1991, pp. 585-897.

[5] Chris Barker, The SAGE Dictionary of Cultural Studies. London, Thousand Oaks, New Delhi: Sage Publications Ltd., 2004, pp. 64-65.

[6] David Holm, Hanvueng: The Goose King and the Ancestral King: an Epic from Guangxi in Southern China. Leiden: Koninklijke Brill NV, 2015, p. IX.

[7] Philippe Cardinal, Contemporary Ethnographic Translation of Traditional Aboriginal Narrative: Textualizations of the Northern Tutchone Story of Crow. Montreal: Concordia University, 2009, pp. 87-88.

[8] David Holm, Hanvueng: The Goose King and the Ancestral King: an Epic from Guangxi in Southern China. Leiden: Koninklijke Brill NV, 2015, p. 1.

[9] David Holm, Hanvueng: The Goose King and the Ancestral King: an Epic from Guangxi in Southern China. Leiden: Koninklijke Brill NV, 2015, pp. X-XI.

[10] David Holm, Hanvueng: The Goose King and the Ancestral King: an Epic from Guangxi in Southern China. Leiden: Koninklijke Brill NV, 2015, p. X.

[11] Huang Zhongxi, David Holm: An Ethnographic Researcher-Translator of the Zhuang People. Journal of Guilin Normal College, 2016, 30 (05), pp. 62-66.
[12] Kwame Anthony Appiah, Thich Translation, in Venti, Lawrence (ed.), The Translation Studies Reader. London and New York: Toutledge, 2000, p. 427.

[13] Wang Zhiguo, Interlingual Writing and Ethnographic Translation of Yi Poetry: with Special Reference to Aku Wuwu's Coyote Traces. Journal of Yanshan University, 2019, 20 (05), pp 37-42.

[14] David Holm, Hanvueng: The Goose King and the Ancestral King: an Epic from Guangxi in Southern China. Leiden: Koninklijke Brill NV, 2015, pp. 287-288.

[15] Huang Zhongxi, On Translator's Notes in Chinese Translation of The New Annotated Version of Mo Scriptures of Zhuang People. Journal of Guilin Normal College, 2018, 32 (03), pp 76-81.

[16] Richard Nordquist. What Is an Annotation in Reading, Research, and Linguistics. Thought Co, Feb. 11, 2020, thoughtco.com/what-is-annotation-1688988.

\section{Biography}

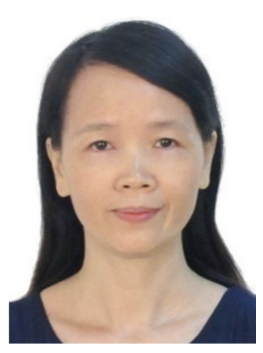

Lu Lianzhi (1970-) is a Zhuang native speaker and a professor of English at Baise University. Her research interests focus on studies of language and culture, and translation of minority classics. 